\title{
Treatment of Lumbar Degenerative Disc Disease Using a Novel, Compressible Core Prosthesis: 24-Month Results
}

\section{Ritter Lang K ${ }^{1 *}$, Dreßler N1, Schätz $C^{2}$ and Gössel $L^{2}$}

${ }^{1}$ Spezialpraxis fur Wirbelsaulenchirurgie, Potsdam, Germany

${ }^{2}$ Orthopadische Klinik Markgroningen gGmbH, Markgroningen, Germany

\begin{abstract}
Background: Low back pain is one of the most prevalent problems in industrialized countries and often results in decline in the quality of life of the affected individuals. There are a number of contributors to low back pain, one of which is Degenerative Disc Disease (DDD) of the spine. Although fusion has been well accepted for the treatment of $\mathrm{DDD}$, high rates of complications and stress to adjacent segments remain a concern. Lumbar Total Disc Replacement (LTDR) is one technology that has become popular as an alternative to fusion. Artificial disc replacements were developed with a goal of preserving motion and avoiding various fusion-related complications.
\end{abstract}

Methods: This is a multi-center, single arm, prospective post-market registry of the M6 ${ }^{\circledR}-\mathrm{L}$, a compressible core TDR, consisting of consecutive patients presenting with lumbar DDD who agreed to participate. Clinical outcome measures include the Oswestry Disability Index (ODI) and back and leg Visual Analogue Scales (VAS). Data was collected pre-operatively, peri-operatively and post-operatively at 6 weeks, 3,6 and 12 months and yearly thereafter. AP, Lateral and flexion/extension x-rays were performed for radiographic analysis. Patients are monitored continuously to track complications.

Results: Results for 45 patients, (20 males, 25 females, mean age 44.6 years) are reported. Thirty-one patients were treated at 1 level, and 14 at multiple levels, between L3 and S1. Mean ODI has decreased significantly $(p<0.001)$ from $45.9 \pm 16.5 \%$ at baseline to $19.7 \pm 19.3$ at 2 years post-implant. Low back pain has also decreased significantly $(p<0.001)$ from baseline with a preoperative back pain VAS of 7.0 and a 2 year value of 2.5. Physiologic range of motion was maintained from baseline through 2 years.

Conclusions: Two year results from the post-market registry suggest initial device safety and effectiveness when used for the treatment of lumbar degenerative disc disease.

Keywords: Total disc replacement; Degenerative disc disease; Low back pain

\section{Introduction}

Low back pain is one of the most prevalent problems in industrialized countries and often results in decline in the quality of life of the affected individuals. There are a number of contributors to low back pain, one of which is Degenerative Disc Disease (DDD) of the spine [1]. Degenerative disc disease can lead to chronic low back pain and is defined by a series of events which may cause inflammation, disc dehydration and restricted mobility of the spine [2]. In addition to non-operative management of the condition, patients who experience uncontrolled low back pain as a result of DDD may take advantage of numerous therapeutic techniques. Until the emergence of lumbar artificial discs, lumbar fusion surgery was considered to be the standard of care in such instances. Lumbar fusion is designed to eliminate the motion and instability of the affected vertebral region, thus decreasing low back pain. Unfortunately, fusion is associated with complications and intensifies the stress to adjacent levels resulting in loss of disc height, collapse, abnormal segment motion and degeneration. Total disc replacement surgery has emerged as a way to preserve motion of the affected segment and to potentially decrease the incidence of adjacent disc degeneration [2,3]. Previous clinical studies of lumbar artificial discs have shown non-inferiority to lumbar fusion at 2 years post-op in clinical and radiographic outcomes [4-7]. However, more recent publications have indicated sustained clinical and radiographic outcomes at 5 years in addition to re-analysis of original 2 year data resulting in possible clinical superiority to fusion for some clinical outcomes $[8,9]$.

The M6'-L Artificial Lumbar Disc System (Spinal Kinetics, Inc., Sunnyvale, CA) is an advanced generation intervertebral disc designed to maintain motion of a functional spinal unit by replicating anatomic, physiologic and biomechanical characteristics of the native disc. The device is comprised of an assembly of high-tensile strength, Ultra-High-Molecular-Weight Polyethylene (UHMWPE) fibers wound in multiple redundant layers around a Polycarbonate Urethane Polymer (PCU) core and through titanium alloy endplates. The polymer core is designed to simulate the structure of the nucleus and the fibers are designed to simulate the annulus. This unique design provides a progressive resistance to motion and enables the device to have all six degrees of freedom. The disc also has a polycarbonate urethane polymer sheath surrounding the core and fiber construct to minimize tissue in growth as well as the migration of wear debris. Serrated keels located on the exterior surfaces of the device provide acute fixation to the superior and inferior vertebral bodies. Both the endplates and keels are coated with porous titanium to increase bone contact surface area and promote osseointegration (Figure 1). The device is intended to replace the degenerative disc, restore and maintain

*Corresponding author: Karsten Ritter-Lang, Spezialpraxis für Wirbelsäulenchirurgie Rudolf-Strasse 22 Breitscheid 14482 Potsdam Brandenberg Germany, Tel: +49 (0)3317409700, Email: k.ritter-lang@wirbelsaeule-potsdam.de, Ibeeman@austin.rr.com

Received November 09, 2013; Accepted December 10, 2013; Published December 20, 2013

Citation: Ritter Lang K, Dreßler N, Schätz C, Gössel L (2013) Treatment of Lumbar Degenerative Disc Disease Using a Novel, Compressible Core Prosthesis: 24-Month Results. J Spine 2: 147. doi:10.4172/2165-7939.1000147

Copyright: (c) 2013 Ritter Lang K, et al. This is an open-access article distributed under the terms of the Creative Commons Attribution License, which permits unrestricted use, distribution, and reproduction in any medium, provided the original author and source are credited. 


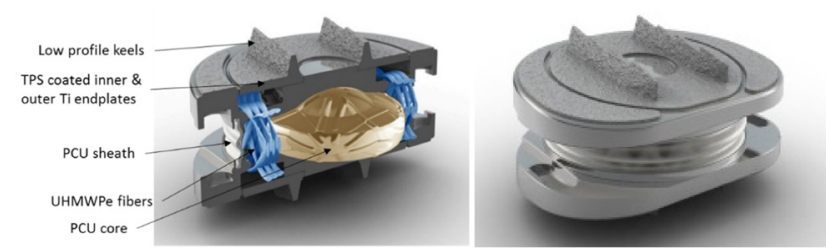

Figure 1: M6-L Components \& Finished Device.

normal segmental motion without affecting adjacent segments, and achieve a good clinical outcome.

\section{Materials and Methods}

This is an ongoing multi-center, single arm, prospective postmarket registry. Consecutive patients presenting for surgery with lumbar degenerative disc disease, who gave consent to participate, were enrolled. The Investigators were instructed to select patients according to the Instructions For Use (IFU) and perform the surgery according to the Surgical Technique Manual. The key inclusion/exclusion criteria are presented in Table 1.

This study presents data obtained from all patients enrolled during the first year of the registry from February 2010 to March 2011 who have completed the 24 month follow-up visit.

Patient history, neurological examination specific to low back pain, the Oswestry Disability Index [10,11] (ODI) questionnaire, back and leg pain Visual Analogue Scales [12] (VAS) and incidence and severity of complications were collected and evaluated. Study visits consisted of pre-operative and post-operative visits at 4-6 weeks, 3,6,12 and 24 months after surgery. Additional long-term follow-up will continue.

The Oswestry Disability Index (ODI) is one of the most commonly used outcome measures for spinal disabilities [10,11]. It is designed to give information as to how back pain has affected patient's ability to manage everyday life. It consists of 10 different categories ranging from pain intensity and personal care to walking, lifting and standing. Each of these categories has a total of five possible answers; the higher the score, the higher the disability. The ODI has been subjected to numerous reviews and still remains a valid measure of various spine-related disabilities [10]. Because the questionnaire is self-administered and lacks any open-ended questions, it safeguards against any interviewer bias thus leading to reliability and uniformity of presentation [11].

The Visual Analogue Scale (VAS) is a measurement instrument consisting of a $10 \mathrm{~cm}$ continuous line anchored on one end with "no pain" and on the other end with "worst pain ever" [12]. Patients can indicate their response by placing a vertical mark on the continuous scale designating their pain level. For the purpose of this study the VAS was used to measure back and leg pain. Scores are reported out of 10 possible points. A high score indicates higher pain intensity. A major advantage of VAS is its ratio scale properties which allows for easy comparison between percentage differences in various points in time [12].

Neutral Antero Posterior (AP), neutral lateral, and Flexion/ Extension (F/E) X-rays were performed pre-operatively, immediately post-operatively (neutral AP and lateral only) and were to be performed at each follow-up visit thereafter. In an effort to minimize patient radiation exposure, the investigators were permitted to bypass the early post-op x-rays if it was outside of their standard of care $\mathrm{x}$-ray protocol. Qualitative (e.g. device migration, subsidence) and quantitative (e.g. range of motion, disc height, disc angle) outcomes were assessed by a core laboratory (Medical Metrics, Inc., Houston, TX). Flexion/ Extension x-ray images were used to derive Range of Motion (ROM) in degrees. Longitudinal changes in disc height and disc angle were reported.

\section{Surgical technique}

Implantation was accomplished through an anterior transperitoneal or retroperitoneal abdominal approach. In this technique, following the approach and identification of the target disc space, the midline is determined and marked. A complete discectomy is performed and the disc space prepared by removal of cartilaginous material, preserving the bony endplates. Posterior mobilization and restoration of posterior height is accomplished with an intervertebral distractor. The endplate size is determined. A Trial Implant of appropriate footprint, posterior height and lordosis angle is inserted into the disc space under close fluoroscopic control and referenced to the midline marker. Upon fluoroscopic verification of correct Trial Implant location, Chisels are used to create keel tracks into the superior and inferior endplates while the Trial remains as a guide. The Trial and Chisels are removed and the artificial disc is implanted using an Implant Inserter under fluoroscopic visualization.

\section{Statistical methods}

Clinical statistical analyses were performed utilizing Predictive Analytics Software (v.18, SPSS Inc., Chicago, IL) and were based on all available data for all patients who had completed 24 month visits as of February 2013. Descriptive statistics (mean and standard deviation) were employed to characterize results for continuous variables and their differences. Categorical variables were reported with frequencies or percentages as appropriate. Longitudinal change between pre-operative and post-operative visits was calculated and statistical significance value ( $p$-value) was determined using the paired $\mathrm{t}$-test based on the differences. Radiographic statistical analyses were performed using a paired t-test.

To further evaluate the effectiveness of the surgery, the minimum clinically important difference or the smallest differences that the patient considers beneficial for both ODI and back pain VAS were determined $[13,14]$. The incidence and status of any complication was documented at each follow-up visit. Adverse events related to device safety such as subsidence, migration or expulsion, which may require additional surgical intervention, were recorded. Success was assessed using a composite measure defined as (i) increase in function reflected by a 10 percent point decrease in ODI; (ii) decrease of back pain VAS by $1.8 \mathrm{~cm}$; (iii) no complications, defined as re-operations, revisions, device removals or device-related serious adverse events.

\section{Results}

Seventy five (75) patients were enrolled in the first year of the study and 45 had completed their 24 month follow-up visits by February 2013. There were 20 males and 25 females with a mean age of 44.6 years. The mean height and weight were $172.1 \mathrm{~cm}$ and $76.7 \mathrm{~kg}$, respectively. Average BMI for the study patients was 25.8 (Table 2). Thirty-one (31) patients were treated at 1 level, and 14 at multiple levels, between L3 and S1 (Table 3). The average surgery time for all patients in the registry was $84.4 \pm 36.9$ minutes for single level cases and $111.2 \pm 44.5$ for multiple level cases. Blood loss during surgery was $201.7 \mathrm{cc}$ (median $155.0 \mathrm{cc}$ ). The overall mean hospital stay duration was 6.2 days (median 6.0), which is longer than one might expect to see in some markets, but is consistent with standard local healthcare practices. 
Citation: Ritter Lang K, Dreßler N, Schätz C, Gössel L (2013) Treatment of Lumbar Degenerative Disc Disease Using a Novel, Compressible Core Prosthesis: 24-Month Results. J Spine 2: 147. doi:10.4172/2165-7939.1000147

Page 3 of 6

\begin{tabular}{|l|l|}
\hline Inclusion Criteria: & Exclusion Criteria: \\
\hline Between 18 and 75 years of age & Osteopenia or osteoporosis \\
\hline Treatment at one or two adjacent levels between L3 and S1 & $\begin{array}{l}\text { Have a history of endocrine or metabolic disorders. Have rheumatoid arthritis or other } \\
\text { autoimmune disease or a systemic disorder such as HIV or active hepatitis. }\end{array}$ \\
\hline $\begin{array}{l}\text { Have not responded to at least } 6 \text { months of non-operative, conservative } \\
\text { management }\end{array}$ & $\begin{array}{l}\text { Prior intra-abdominal or retroperitoneal surgery that would make the approach prohibitively } \\
\text { dangerous, or prior anterior surgery at the same level }\end{array}$ \\
\hline $\begin{array}{l}\text { Have symptomatic degenerative disc disease (DDD) demonstrated by signs } \\
\text { and/or symptoms of disc herniation, osteophyte formation, or loss of disc height }\end{array}$ & Have uncontrolled insulin dependent type 1 or type 2 diabetes \\
\hline & Require a treatment (e.g.,posterior element decompression) that destabilizes the spine. \\
\hline & $\begin{array}{l}\text { Isolated radicular compression syndromes, especially due to disc herniation } \\
\text { Bony lumbar stenosis, pars defect, increased segmental instability, spinal deformities, } \\
\text { spondylolisthesis above 3mm at the involved level(s) }\end{array}$ \\
\hline Radiological confirmation of severe facet joint disease or degeneration & \\
\hline
\end{tabular}

Table 1: Inclusion/Exclusion criteria.

\begin{tabular}{|l|c|c|}
\hline Gender: & & Female \\
\hline & Male & $\mathbf{2 5} \mathbf{( 4 5 \% )}$ \\
\hline Age in years & (Mean \pm SD) & $44.6 \pm 8.2$ \\
\hline Height in $\mathrm{cm}$ & (Mean \pm SD) & $172.1 \pm 10.1$ \\
\hline Weight in $\mathrm{kg}$ & (Mean \pm SD) & $76.7 \pm 14.9$ \\
\hline BMl & (Mean \pm SD) & $25.8 \pm 3.7$ \\
\hline
\end{tabular}

Table 2: Baseline Characteristics.

\begin{tabular}{|c|c|}
\hline Index Level(s) & n (\%) of pts \\
\hline L4/L5 & $8(-17.8 \%)$ \\
\hline L5/S1 & $23(-51.1 \%)$ \\
\hline L3/L4; L4/L5 & $3(-6.7 \%)$ \\
\hline L4/L5; L5/S1 & $10(-22.2 \%)$ \\
\hline L3/L4; L4/L5; L5/S1* & $1(-2.2 \%)$ \\
\hline
\end{tabular}

*Although the IFU for the M6 -L device indicates implantation of the device at 1 or 2 levels from $L 3-S 1$, the decision to implant the device at 3 levels was made for one patient

Table 3: Surgery Levels.

\section{Clinical outcomes}

The mean ODI was $45.9 \pm 16.5 \%$ at baseline, and had improved by $57 \%$ at 24 months (Figure 2). This was a highly significant improvement in overall mean ODI $(\mathrm{p}<0.001)$. According to the literature, a 10-point improvement in ODI is considered the Minimum Clinically Important Difference (MCID) [14]. In this study, $78 \%$ of the patients achieved MCID at 24 months. The mean ODI improvement from baseline to 24 months follow-up was 26 percentage points.

According to ODI criteria, $93.3 \%(n=42)$ of the study population had a disability of moderate to bed-bound pre-operatively, with only $6.7 \%$ reporting minimal disability. At the 24 -month follow-up, $62.2 \%$ of the patients reported minimal disability. The level of patient disability pre-operatively and at 24 months is shown in Figure 3.

Back pain was $7.0 \pm 2.0$ pre-operatively on the visual analogue scale. Mean right and left leg pain scores were $3.5 \pm 3.2$ and $3.9 \pm$ 3.1, respectively (Figure 4). At 24 months follow-up mean pain VAS decreased significantly for all 3 measures with back pain score averaging $2.5 \pm 2.6$, right leg pain $1.1 \pm 1.9$ and left leg pain $1.7 \pm 2.7$. Back pain decreased by $64 \%$, right leg pain by $68 \%$, and left leg pain by $56 \%$ at 24 months.

It has been reported that an improvement of $1.8-1.9 \mathrm{~cm}$ in VAS back pain can be equivalent to the minimum clinically important difference [14]. In this cohort, $77.8 \%$ of the patients achieved MCID based on $1.8 \mathrm{~cm}$ improvement in back pain VAS.
Thirty-four (34) patients, or $76 \%$ of the patient population, completed a patient satisfaction survey at 24 months post-op. Eighty eight percent (30 patients) responded that their condition was greatly improved and $97 \%$ (32 of 33) reported willingness to undergo surgery again under the same circumstances.

\section{Radiographic outcomes}

Radiographic outcomes were derived from longitudinal data on disc angle, anterior and posterior disc height, index and global range of motion analysis. Due to concerns about the effects of $\mathrm{x}$-ray radiation, not all study participants completed all radiographic analyses at each time point; all available data were included in the analyses. At 24 month follow-up, thirty-seven (37) study participants completed the neutral radiographs required to assess disc angle, anterior and posterior disc height; eighteen (18) and nineteen (19) completed the flexion/extension radiographs required to assess global and index range of motion, respectively. Figures 5 and 6 show a comparison of pre and post-operative lateral $\mathrm{x}$-rays over time for a single level disc replacement at L5/S1. Both anterior and posterior mean disc height increased significantly over the course of the study (Figure 7). At baseline, anterior disc height was $10.2 \pm 3.1 \mathrm{~mm}$ and increased to 17.7 $\pm 2.9 \mathrm{~mm}$ at 24 months follow-up $(\mathrm{p}<0.0001)$. Posterior disc height increased significantly from $3.9 \pm 1.6 \mathrm{~mm}$ pre-operatively to $7.6 \pm 1.9$ $\mathrm{mm}$ at 24 months follow-up $(\mathrm{p}<0.0001)$.

An increase in average disc angle was also observed at all follow- 
up time points compared to baseline (Figure 8). At the immediate post-operative visit, the disc angle had increased by more than $60 \%$ and this increase was maintained throughout all follow-up time points $(\mathrm{p}<0.0001)$.

Global range of motion for this group was maintained throughout the follow-up time period with a slight increase from $38.0^{\circ}$ preoperatively to $40.6^{\circ}$ at 24 months. Index level range of motion was also maintained from baseline through the 24 month follow-up (Figure 9).

\section{Clinical success and patient safety}

As indicated previously, individual patient success was assessed using a composite measure encompassing changes in ODI and VAS and lack of relevant complications. According to the composite

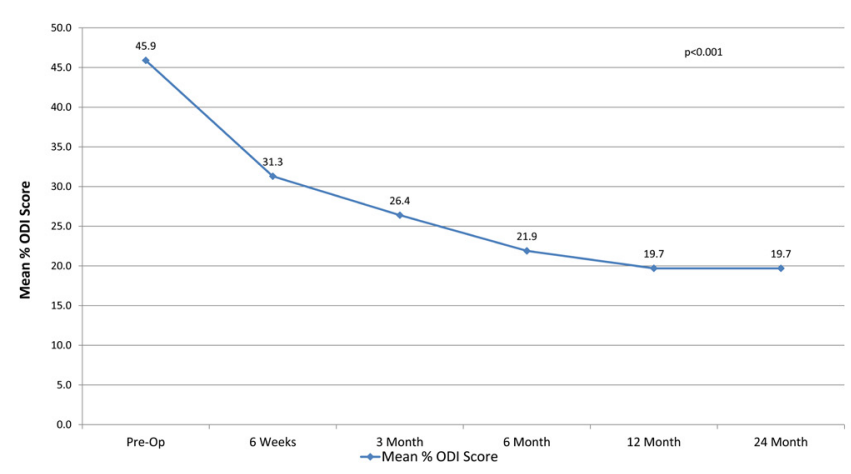

Figure 2: Mean Oswestry Disability Index.

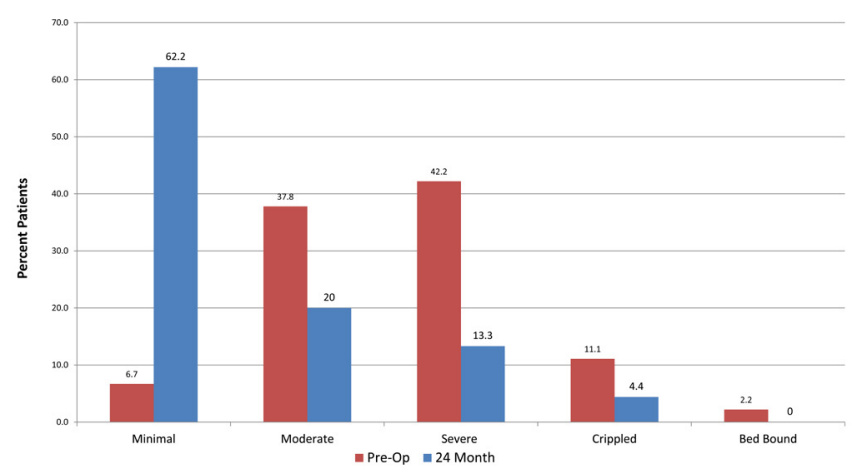

Figure 3: Disability Level at baseline and 24 Months.

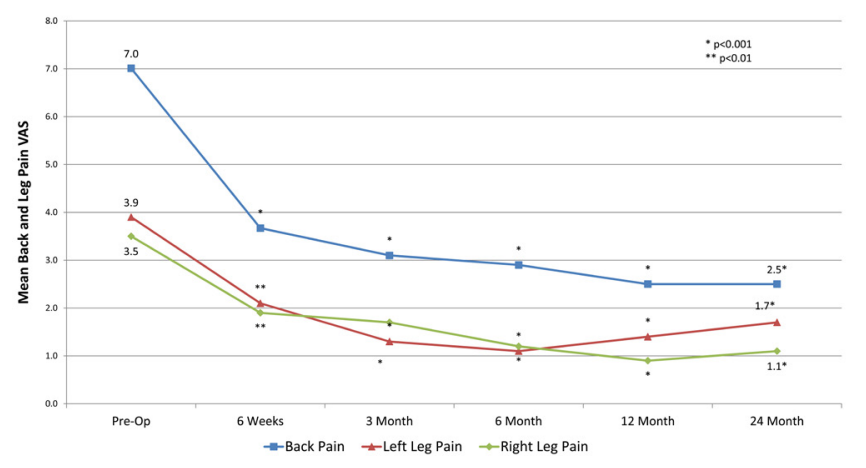

Figure 4: Back and Leg Pain.

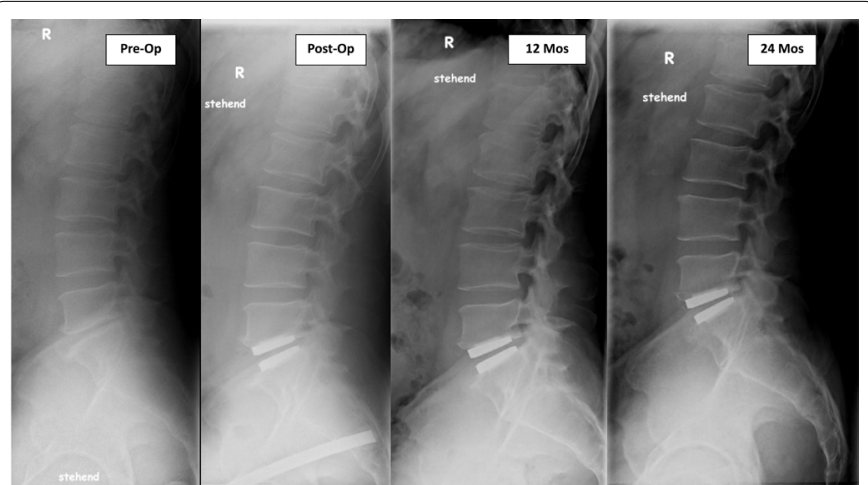

Figure 5: Lateral radiographs of the lumbar spine including the index level, for single level disc replacement at L5/S1.

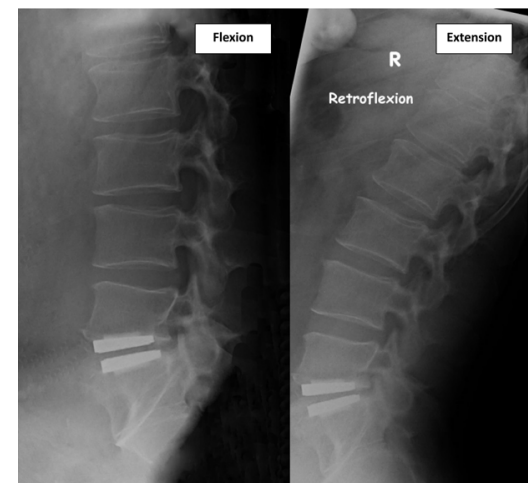

Figure 6: Flexion/Extension radiographs at 24 months.

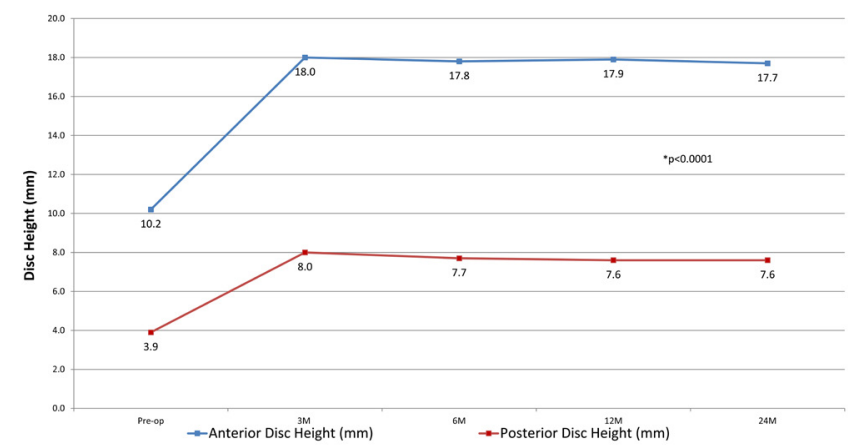

Figure 7: Anterior and Posterior Disc Height.

measure for success, at 24 months overall clinical success was attained for $73.3 \%(n=33)$ of the patients. There were no reported procedural complications, revisions, device removals or device-related serious adverse events, nor were there any other reported unanticipated or serious adverse device effects.

\section{Discussion}

Low back pain is one of the most prevalent problems in industrialized countries and often results in decline in the quality of life of the affected individuals. There are a number of contributors to low back pain, one of which is degenerative disc disease of the spine [1]. Although fusion has been well accepted for the treatment of DDD, high rates of complications and stress to adjacent segments remain a major concern. It has been reported that up to $20 \%$ of fusion patients have required 

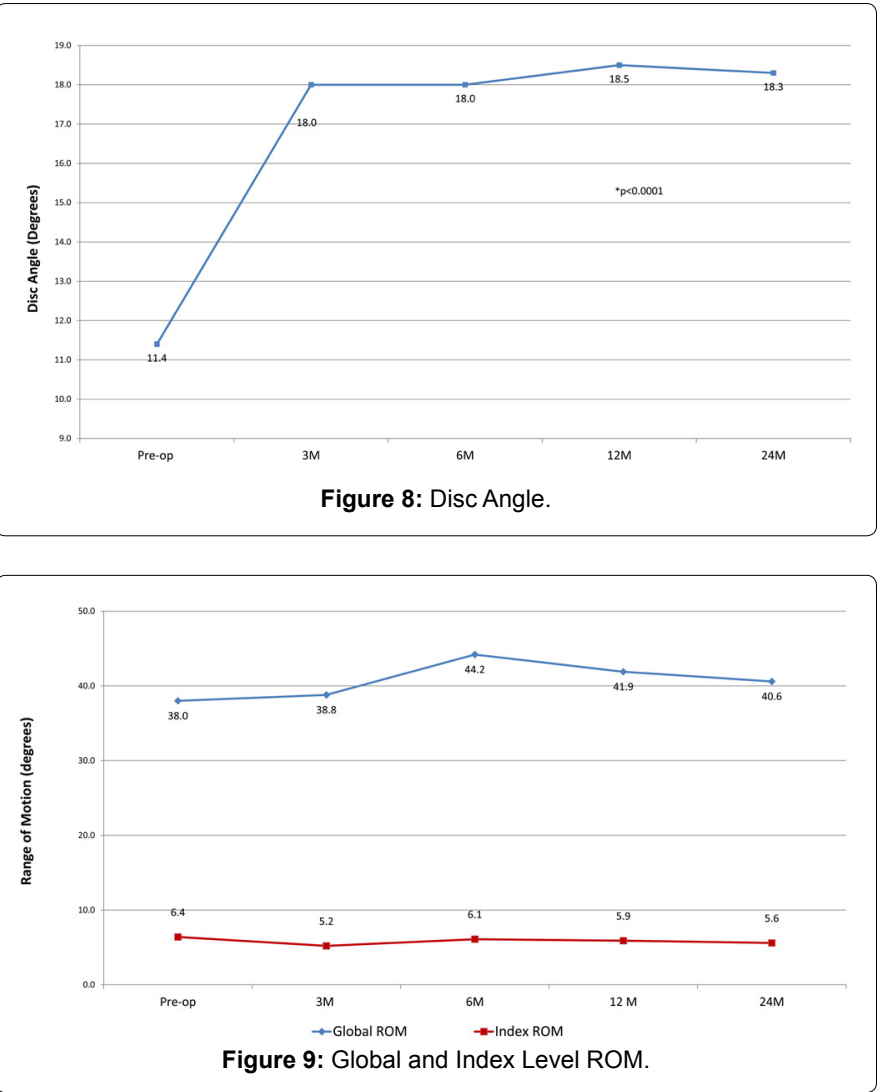

surgery at an adjacent level [15]. This increased risk associated with fusion led to a paradigm shift towards innovative technologies that aim to preserve motion and reduce adjacent level disc degeneration $[15,16]$. Total Lumbar Disc Replacement (TDR) is one such technology that has since become more popular as an alternative to fusion. Artificial disc replacement devices were developed with a goal of preserving motion and avoiding various fusion-related complications [3]. The compressible core device studied herein is intended to further mimic the natural function of the lumbar disc in an attempt to better preserve the kinematics and biomechanics of the affected spinal segment.

The clinical outcomes of total disc replacement reported in this study for the compressible core device are consistent with those reported for other arthroplasty devices. At two years, $78 \%$ of the study population in this limited study reported clinical success as measured by ODI scores, with an average improvement of $57 \%$ from baseline. Data from the literature were comparable, with reports of ODI success ranging from 73 to $77 \%$ of the study population for both single-level and two-level ProDisc implanations at 2 to 5 years (improvement of 44-66\% from baseline) [3,5,17-19]; improvements of $47-51 \%$ in ODI at 2 to 5 years after implantation with the Charite disc $[4,8,20] ; 47-63 \%$ improvements after 2 years of implanation of a Maverick disc [6,21]; and $52-62 \%$ improvements in ODI in studies examining more than one type of TDR $[22,23]$. VAS scores in the present study indicated an improvement of $64 \%$ in back pain and $56 \%$ in leg pain at two years. While reports in the literature varied in the VAS measure reported, VAS score improvement was similar, ranging from $41-79 \%$ when a general VAS pain score was reported [4,5,8,17-20,23]; from $58-75 \%$ for back pain VAS $[3,6,21,22]$; and 46 to $64 \%$ for leg pain VAS $[3,6,21,22]$. Individual patient success is an even more difficult measure to assess among studies, as the measures utilized by different authors varied. In this study, individual patient success was defined using a composite measure and was found to be $73 \%$, which is comparable to reported overall patient success in the TDR literature [24].

The disc angle and disc height at the index level were found to have increased after TDR. The observed increases in disc angle of about $6^{\circ}$ are consistent with the observations of several investigators who have examined the effect of lumbar TDR on sagittal balance and found that the overall lordosis is either unchanged or improved, while the index segmental lordosis is increased. For example, LeHuec et al. [25] measured the segmental and overall lordosis of 35 patients who received single-level Maverick TDRs and reported that the segmental lordosis increased significantly at the index level $\left(5.1^{\circ}\right.$ at L4-L5, $4.9^{\circ}$ at L5-S1). Cakir et al. [26] studied segmental and overall lordosis after implantation of the ProDisc in 29 patients and similarly found an increase (average of $8.4^{\circ}$ ) in segmental lordosis. Several other authors, reporting on clinical or biomechanical studies of segmental lordosis changes after TDR with a variety of implants [27-31], similarly found significant increases in segmental lordosis. Since the sagittal balance is either unchanged or improved, the increase in angle after TDR is likely restorative. Likewise, disc height restoration been observed after TDR with several different prostheses [31,32] and is in fact often a stated goal of the procedure. Siepe et al. [31] reported anterior height increases of an average of $6.9 \mathrm{~mm}$ anteriorly, and $3.4 \mathrm{~mm}$ posteriorly, after implantation of a ProDisc II. As noted by the authors of this study, this relatively larger increase in the anterior height relative to the posterior height is directly related to an increase in the disc angle.

Both the global and segmental range of motion remained relatively unchanged from pre-op through 24 months; there was no statistically significant difference between the preoperative ROM and that at any other time point for either measure. Reports from the literature reflect a lack of consistency in the ROM achieved at the index level after TDR with a variety of articulating prostheses [6,27,31,33-35]. One possible reason for this variation could be varying surgical procedures and the degree to which the PLL is resected. Since all anterior TDR procedures sacrifice the ALL, there can be an imbalance in the forces permitting flexion and extension motion. The M6-L, which provides a progressive resistance to motion in both flexion and extension, may permit a more natural or balanced range of motion, particularly if the PLL is fully resected.

This study reports results from forty-five patients followed in a post-market registry. Despite the limitations imposed by the sample size and study type, a registry is an effective tool that allows for data to be collected on patients treated according to standard of care and demonstrates the results of the treatment in a real-life setting. The data from the registry indicate that the compressible core device behavior and results are promising and are consistent with that observed in other TDRs.

\section{Conclusion}

The purpose of a TDR is to provide improved, physiologic disc height and range of motion, which in turn may lead to less wear and stress on adjacent vertebral levels and have a positive effect on clinical outcomes. The improvements in clinical outcomes reported in this registry study, such as disability and pain relief, and the radiographic outcomes, including maintenance of range of motion and physiologic disc height and disc angle at the affected level, suggest that the compressible core device behaves as intended, with an adequate initial safety and effectiveness profile at the two year time point. As in the case of other lumbar artificial discs, a larger sample size and extended 
follow-up are necessary; the post-market registry continues for this purpose.

\section{References}

1. Policy statement on lumbar spinal fusion surgery (2011) International Society for the Advancement of Spine Surgery (ISASS).

2. Canbulat N, Sasani M, Ataker Y, Oktenoglu T, Berker N, et al. (2011) A rehabilitation protocol for patients with lumbar degenerative disk disease treated with lumbar total disk replacement. Arch Phys Med Rehabil 92: 670676.

3. Blondel B, Tropiano P, Gaudart J, Marnay T (2011) Clinical results of total lumbar disc replacement regarding various aetiologies of the disc degeneration: a study with a 2-year minimal follow-up. Spine (Phila Pa 1976) 36: E313-319.

4. Blumenthal S, McAfee PC, Guyer RD, Hochschuler SH, Geisler FH, et al. (2005) A prospective, randomized, multicenter food and drug administration investigational device exemptions study of lumbar total disc replacement with the charite artificial disc versus lumbar fusion: Part i: Evaluation of clinical outcomes. Spine 30: 1565-1575.

5. Zigler J, Delamarter R, Spivak JM, Linovitz RJ, Danielson GO, et al (2007) Results of the prospective, randomized, multicenter food and drug administration investigational device exemption study of the prodisc-I total disc replacement versus circumferential fusion for the treatment of 1-level degenerative disc disease. Spine 32: 1155-1162.

6. Gornet MF, Burkus JK, Dryer RF, Peloza JH (2011) Lumbar disc arthroplasty with maverick disc versus stand-alone interbody fusion: A prospective, randomized, controlled, multicenter investigational device exemption trial. Spine 36: E1600-1611.

7. Sasso RC, Foulk DM, Hahn M (2008) Prospective, randomized trial of metalon-metal artificial lumbar disc replacement: Initial results for treatment of discogenic pain. Spine 33: 123-131.

8. Guyer RD, McAfee PC, Banco RJ, Bitan FD, Cappuccino A, et al. (2009) Prospective, randomized, multicenter Food and Drug Administration investigational device exemption study of lumbar total disc replacement with the CHARITE artificial disc versus lumbar fusion: five-year follow-up. Spine $J$ 9: 374-386.

9. Geisler FH (2007) Surgical treatment for discogenic low-back pain: Lumbar arthroplasty results in superior pain reduction and disability level improvement compared with lumbar fusion. SAS Journal 1: 12-19.

10. Fairbank JC, Couper J, Davies JB, O'Brien JP (1980) The Oswestry low back pain disability questionnaire. Physiotherapy 66: 271-273.

11. Fairbank JC, Pynsent PB (2000) The Oswestry Disability Index. Spine (Phila Pa 1976) 25: 2940-2952.

12. Katz J, Melzack R (1999) Measurement of pain. Surg Clin North Am 79: 231252

13. Copay AG, Glassman SD, Subach BR, Berven S, Schuler TC, et al. (2008) Minimum clinically important difference in lumbar spine surgery patients: A choice of methods using the oswestry disability index, medical outcomes study questionnaire short form 36, and pain scales. Spine J 8: 968-974.

14. Hägg O, Fritzell P, Nordwall A; Swedish Lumbar Spine Study Group (2003) The clinical importance of changes in outcome scores after treatment for chronic low back pain. Eur Spine J 12: 12-20.

15. Wilson-MacDonald J, Boeree N (2007) Controversial topics in surgery: Degenerative disc disease: Disc replacement. Ann R Coll Surg Engl 89: 6-11.

16. Siepe CJ, Mayer HM, Wiechert K, Korge A (2006) Clinical results of total lumbar disc replacement with ProDisc II: three-year results for different indications. Spine (Phila Pa 1976) 31: 1923-1932.

17. Delamarter R, Zigler JE, Balderston RA, Cammisa FP, Goldstein JA, et al. (2011) Prospective, randomized, multicenter food and drug administration investigational device exemption study of the prodisc-I total disc replacement compared with circumferential arthrodesis for the treatment of two-level lumbar degenerative disc disease: Results at twenty-four months. J Bone Joint Surg Am 93: 705-715.

18. Park CK, Ryu KS, Lee KY, Lee HJ (2012) Clinical outcome of lumbar total disc replacement using ProDisc-L in degenerative disc disease: minimum 5-year follow-up results at a single institute. Spine (Phila Pa 1976) 37: 672-677.

19. Zigler JE, Delamarter RB (2012) Five-year results of the prospective, randomized, multicenter, food and drug administration investigational device exemption study of the prodisc-I total disc replacement versus circumferential arthrodesis for the treatment of single-level degenerative disc disease. $J$ Neurosurg Spine 17: 493-501.

20. Guyer RD, Thongtrangan I, Ohnmeiss DD (2012) Outcomes of charite lumbar artificial disk versus fusion: 5-year data. Seminars in Spine Surgery 24: 32-36.

21. Le Huec JC, Mathews H, Basso Y, Aunoble S, Hoste D, et al. (2005) Clinica results of Maverick lumbar total disc replacement: two-year prospective followup. Orthop Clin North Am 36: 315-322.

22. Berg S, Tullberg T, Branth B, Olerud C, Tropp H (2009) Total disc replacement compared to lumbar fusion: a randomised controlled trial with 2-year follow-up. Eur Spine J 18: 1512-1519.

23. Guyer RD, Pettine KA, Knight RQ, Dimmig TA, Coric D, et al. Direct comparison of two lumbar total disc replacement devices: Results from a prospective, randomized, multicenter fda-regulated trial. Proceedings of Conference Direct comparison of two lumbar total disc replacement devices: Results from a prospective, randomized, multicenter fda-regulated trial.

24. Thavaneswaran $P$, Vandepeer $M(2013)$ Lumbar artificial intervertebral disc replacement: a systematic review. ANZ J Surg.

25. Le Huec J, Basso Y, Mathews H, Mehbod A, Aunoble S, et al. (2005) The effect of single-level, total disc arthroplasty on sagittal balance parameters: a prospective study. Eur Spine J 14: 480-486.

26. Cakir B, Richter M, Käfer W, Puhl W, Schmidt R (2005) The impact of tota lumbar disc replacement on segmental and total lumbar lordosis. Clin Biomech (Bristol, Avon) 20: 357-364

27. Chung SS, Lee CS, Kang CS, Kim SH (2006) The effect of lumbar total disc replacement on the spinopelvic alignment and range of motion of the lumbar spine. J Spinal Disord Tech 19: 307-311.

28. Huang RC, Girardi FP, Cammisa Jr FP, Tropiano P, Marnay T (2003) Longterm flexion-extension range of motion of the prodisc total disc replacement. $J$ Spinal Disord Tech 16: 435-440.

29. O'Leary P, Nicolakis M, Lorenz MA, Voronov LI, Zindrick MR, et al. (2005) Response of Charité total disc replacement under physiologic loads: prosthesis component motion patterns. Spine J 5: 590-599.

30. Schmidt R, Obertacke U, Nothwang J, Ulrich C, Nowicki J, et al. (2010) The impact of implantation technique on frontal and sagittal alignment in total lumbar disc replacement: a comparison of anterior versus oblique implantation. Eur Spine J 19: 1534-1539.

31. Siepe CJ, Hitzl W, Meschede P, Sharma AK, Khattab MF, et al. (2009) Interdependence between disc space height, range of motion and clinical outcome in total lumbar disc replacement. Spine 34: 904-916.

32. Tournier C, Aunoble S, Le Huec JC, Lemaire JP, Tropiano P, et al. (2007) Total disc arthroplasty: consequences for sagittal balance and lumbar spine movement. Eur Spine J 16: 411-421.

33. Ross R, Mirza AH, Norris HE, Khatri M (2007) Survival and clinical outcome of SB Charite III disc replacement for back pain. J Bone Joint Surg Br 89: 785-789.

34. McAfee PC, Cunningham B, Holsapple G, Adams K, Blumenthal S, et al. (2005) A prospective, randomized, multicenter food and drug administration investigational device exemption study of lumbar total disc replacement with the charite artificial disc versus lumbar fusion: Part ii: Evaluation. Spine (Phila Pa 1976). 30:1576-1583

35. Huang RC, Girardi FP, Cammisa FP Jr, Lim MR, Tropiano P, et al. (2005) Correlation between range of motion and outcome after lumbar total disc replacement: 8.6-year follow-up. Spine (Phila Pa 1976) 30: 1407-1411. 